\title{
CONTRATOS DE PARCERIAS PÚBLICO-PRIVADAS NA GESTÃO DE RESÍDUOS SÓLIDOS URBANOS - ESTUDOS DE CASO
}

Public private partnerships in solid waste management - case study

${ }^{1}$ Escola de Contas do Tribunal de Contas do Município de São Paulo. São Paulo/SP, Brasil. Correspondência: Christine Parmezani Munhoz. E-mail: chrismunhoz@yahoo.com.br.

Recebido em: 29/01/2015. Revisado em: 03/07/2015. Aprovado em: 06/07/2015. 


\section{RESUMO}

O objetivo deste artigo é analisar a concessão administrativa (Lei n. 11.079/2004 - Parcerias Público-Privadas, PPPs) na gestão de resíduos sólidos urbanos e verificar a adequação desses contratos às diretrizes da Lei n. 12.305/2010 - Política Nacional de Resíduos Sólidos (PNRS). A metodologia consistiu no estudo de caso em dois editais e minutas de contrato de PPPs, no município de São Carlos e na Região Metropolitana de Belo Horizonte e Colar Metropolitano. Foi realizado o mapeamento dos indicadores de desempenho desses contratos, segundo quatro critérios: (a) minimização de resíduos; (b) valorização e tratamento de resíduos (reciclagem, compostagem etc.); (c) inclusão de catadores; e (d) participação social. Os resultados indicam que os contratos analisados atendem apenas a uma parte das diretrizes definidas pela PNRS e visam a solucionar principalmente a erradicação dos lixões e a disposição final adequada de resíduos em aterros sanitários. $\mathrm{O}$ objeto principal dos contratos continua vinculado ao antigo paradigma de coleta e transporte de resíduos e operação de aterros sanitários, com captação de gás para geração de energia. Para atender às políticas de minimização de resíduos, há incentivos financeiros para a redução na disposição final em aterros, mas não há metas contratuais fixas para desempenho da concessionária. Caso as políticas de minimização de resíduos, logística reversa e responsabilidade compartilhada sejam implementadas pelas esferas governamentais, os contratos possuem cláusulas de revisões periódicas para ajustes graduais, preservando o equilíbrio econômico-financeiro do contrato. No entanto, é necessário aprofundar a contratação por desempenho, com metas fixas que ampliem o diálogo com as diretrizes da PNRS.

\section{Palavras-Chave}

Gestão de Resíduos; Parceria Público-Privada; Resíduos Sólidos.

\section{ABSTRACT}

This paper analyzes two public notices for PPP (Public-Private Partnerships - Law 11.079/2004) for solid waste management and verifies the suitability of these contracts to the new guidelines of Law 12.305/2010 - National Solid Waste Policy - PNRS. The online versions of 2 public notices and draft PPP Contracts, recently signed in the city of São Carlos and the Metropolitan Area of Belo Horizonte and Colar Metropolitano were analyzed. The mapping of the performance indicators of these documents was carried out according to 4 criteria: (a) minimization of waste in landfills, (b) recovery and valorization of solid waste (recycling, composting, etc.); (c) pickers inclusion; and (d) social participation. The results indicate that the analyzed contracts meet only part of the guidelines set by PNRS, mainly the eradication of the dumps and the final disposal of waste in landfills. The main object of these contracts remains linked to the old paradigm of waste management: collection and transportation of waste and operation of landfills. To meet the waste minimization policies, there are financial incentives that reward the reduction in the final disposal in landfills. However, there are no fixed contractual targets for the minimization of waste at landfills. If waste minimization policies, like reverse logistics and responsibility shared are implemented by the government, the contracts have clauses allowing periodic reviews for gradual adjustments, ensuring the economic and financial balance of the contract. It is yet to determine the efficiency of these mechanisms to meet the guidelines of PNRS, in the curse of the concession.

\section{Keywords}

Public-Private Partnership; Solid Waste; Waste Management. 


\section{Introdução}

As Parcerias Público-Privadas (PPPs) são contratos administrativos de concessão de serviço público, nos quais o parceiro privado é responsável pelo investimento inicial em infraestrutura e pela operação de serviços ao longo da concessão, sendo remunerado pelo governo no longo prazo, em parcelas (contraprestações). Pode-se dizer que é uma forma de financiamento privado da infraestrutura pública.

As PPPs surgiram na Inglaterra para ampliar a capacidade de investimentos públicos em projetos de infraestrutura, como resposta à restrição fiscal da década de 1980. O modelo inicial é a PFI (Private Finance Initiative), modelo de financiamento privado em que o próprio fluxo de receitas do projeto remunera a rentabilidade dos investimentos privados, reduzindo o impacto no endividamento de curto prazo do governo ${ }^{1}$.

No Brasil, a Lei n. 11.079/2004² regulamenta as PPPs e amplia o escopo das concessões comuns (Lei n. 8.987/199533), disciplinando a concessão patrocinada e a concessão administrativa. O que caracteriza cada modalidade é a forma de pagamento das contraprestações públicas: (a) na concessão comum, o pagamento é realizado pela tarifa dos usuários, como, por exemplo, a cobrança de pedágio em rodovias; (b) na concessão patrocinada, a cobrança de tarifa dos usuários não é suficiente para remunerar o projeto, sendo complementada por pagamento público (por exemplo, a construção e operação de linhas de metrô, em que existe cobrança de tarifa dos usuários, com complemento de pagamento público para garantir a remuneração do projeto); e (c) na concessão administrativa, onde não há cobrança de tarifa dos usuários, com pagamento exclusivo por recursos da administração pública (por exemplo, construção de hospitais e presídios) ${ }^{4,5}$.

A Lei n. 11.079/2004 define que PPPs são contratos cujo valor não pode ser inferior a R \$ 20 milhões, com prazo de concessão entre cinco e 35 anos. Esses limites afastam os contratos abrangidos pela Lei n. $8.666 / 1993^{6}$, sendo vedada a contratação exclusiva de mão de obra, equipamentos ou obra pública. Dessa forma,

\footnotetext{
${ }^{1}$ BRITO, Barbara Moreira Barbosa; SILVEIRA, Antônio Henrique Pinheiro. Parceria público-privada: compreendendo o modelo brasileiro. Revista do Serviço Público, Brasilia v. 56, n. 1, p. 7-21, jan./mar. 2005. Disponível em: <seer.enap.gov.br/index.php/RSP/issue/download/38/49>. Acesso em: 11 mar. 2014.

${ }^{2}$ BRASIL. Lei Federal n. 11.079, de 30 de dezembro de 2004. Institui normas gerais para licitação e contratação de parceria público-privada no âmbito da administração pública. Disponível em: <http://www.planalto. gov.br/ccivil_03/_ato2004-2006/2004/lei/L11079compilado.htm>. Acesso em: 29 jan. 2016.

${ }^{3}$ BRASIL. Lei Federal n. 8.987, de 13 de fevereiro de 1995. Dispõe sobre o regime de concessão e permissão da prestação de serviços públicos previsto no art. 175 da Constituição Federal, e dá outras providências. Disponivel em: <http://www.planalto.gov.br/ccivil_03/Leis/L8987compilada.htm>. Acesso em: 29 jan. 2016. ${ }^{4}$ RIBEIRO, Maurício Portugal; PRADO, Lucas Navarro. Comentários à Lei de PPP - Parceria Público-Privada: fundamentos econômico-jurídicos. São Paulo: Malheiros Ed., 2007. p. 239.

${ }^{5}$ DI PIETRO, Maria Sylvia Zanella. Parcerias na administração pública: concessão, permissão, franquia, terceirização, parceria público-privada e outras formas. 7. ed. São Paulo: Atlas, 2009.

${ }^{6}$ BRASIL. Lei Federal n. 8.666, de 21 de junho de 1993. 4Regulamenta o art. 37, inciso XXI, da Constituição Federal, institui normas para licitações e contratos da Administração Pública e dá outras providências. Disponível em: <http://www.planalto.gov.br/ccivil_03/leis/L8666compilado.htm>. Acesso em: 29 jan. 2016.
} 
nas PPPs, assim como nas concessões comuns, a operação dos serviços deve estar atrelada ao investimento realizado em infraestrutura (em obras ou em aquisição de equipamentos) $)^{3}$.

Para a contratação de desempenho, o contrato de PPP deve prever níveis de performance do parceiro privado, com critérios claros, objetivos e indicadores facilmente mensuráveis (Lei n. 11.079/2004, artigo 5º, inciso VII). O contrato deve especificar as metas, os resultados, a condição de eficiência, as obrigações do parceiro privado e o modo como ele será avaliado na operação dos serviços.

Além disso, a Lei n. 11.079/2004, em seu artigo $6^{\circ}$, parágrafo $1^{\circ}$, define que os indicadores de desempenho devem estar vinculados a descontos ou prêmios que impactam diretamente no pagamento das contraprestações públicas. Dessa forma, as PPPs aprofundam a contratação por desempenho, pois, ao contrário das concessões e de outros contratos administrativos, cuja aplicação de multas e penalidades é feita a posteriori, nas PPPs é feito um desconto direto a priori no pagamento (além da aplicação ordinária de outras multas e penalidades, quando for o caso). Por isso, os autores Ribeiro e Prado não recomendam a descentralização de serviços cujo escopo, metas e resultados não possam ser especificados adequadamente em contrato ${ }^{7}$.

Outro ponto a ser observado nas concessões de longo prazo é a atualização tecnológica dos serviços, garantindo a eficiência do contrato ao longo da concessão. A atualização dos serviços deve respeitar as condições estabelecidas inicialmente no contrato, preservando o equilíbrio econômico-financeiro inicialmente acordado ${ }^{8,9,10}$.

Na gestão de resíduos sólidos urbanos, os contratos de PPPs têm sido utilizados para desenvolvimento de infraestrutura e serviços. Cabe averiguar se esses contratos se adequam às diretrizes da Lei n. 12.305/2010 ${ }^{11}$ (a Política Nacional de Resíduos Sólidos, PNRS).

A PNRS estabelece novos paradigmas e normatiza conceitos como: não geração e minimização de resíduos; mudança na prioridade de tratamento dos resíduos (priorizando a valorização e o reaproveitamento dos materiais, através de reciclagem, compostagem, biodigestão entre outras). Também introduz o conceito de rejeito, sendo que a disposição final em aterros deve ser adotada apenas como última alternativa para o tratamento de resíduos. Regulamenta, ainda, a inclusão social e emancipação econômica dos catadores de materiais recicláveis e a participação

${ }^{7}$ RIBEIRO, Maurício Portugal; PRADO, Lucas Navarro. op. cit.

8 Id. Ibid.

${ }^{9}$ DI PIETRO, Maria Sylvia Zanella. op. cit.

${ }^{10}$ MELLO, Celso Antônio Bandeira de. Curso de direito administrativo. 27. ed. rev. atual. até a Emenda Constitucional 64, de 4.2.2010. São Paulo: Malheiros Ed., 2010.

${ }^{11}$ BRASIL. Lei Federal n. 12.305, de 02 de agosto de 2010. Institui a Política Nacional de Resíduos Sólidos; altera a Lei $n^{\circ}$ 9.605, de 12 de fevereiro de 1998; e dá outras providências. Disponível em: <http://www. planalto.gov.br/ccivil_03/_ato2007-2010/2010/lei/I12305.htm>. Acesso em: 29 jan. 2016. 
social no planejamento público, além da logística reversa e da responsabilidade compartilhada pela gestão de resíduos ${ }^{12,13,14}$.

A PNRS regulamentou no Brasil conceitos e práticas de benchmarking internacional. No entanto, a prática internacional tem demonstrado que cabe ao Estado o papel central de articular soluções entre sociedade e mercado, com uma regulação consolidada e clara sobre as políticas de minimização de resíduos e logística reversa ${ }^{15}$.

A regulação estatal pode ser feita de várias formas, entre elas: por instrumentos de comando e controle - que utilizam leis, normas, multas e punições; por instrumentos econômicos - que utilizam tributos, subsídios e incentivos fiscais; e por instrumentos voluntários, baseados na iniciativa dos cidadãos e estimulados pela educação e conscientização. Na gestão de resíduos sólidos, os países europeus atingem os melhores resultados pelo uso articulado desses instrumentos. Cada instrumento possui pontos positivos e negativos, e uma combinação apropriada desses instrumentos também é preconizada pela Agenda $21^{16,17}$.

O diferencial europeu é a regulação estatal na Responsabilidade Estendida ao Produtor (REP), que responsabiliza tanto produtores e importadores como consumidores pelo sistema de gestão e pelos custos da logística reversa (take-back). A REP alivia os custos públicos e responsabiliza o setor privado (produtores e consumidores), ampliando a interface entre poder público e setor privado na busca por soluções. A REP é efetiva porque integra políticas de comando e controle com mecanismos de mercado - com impacto em toda a cadeia produtiva, visto que o produtor é incentivado a repensar o design de materiais e o ciclo de vida dos produtos no reaproveitamento dos materiais ${ }^{18}$.

NaEuropa, em $201040 \%$ dos resíduos descartados foram reciclados/compostados, $22 \%$ foram incinerados e $38 \%$ foram dispostos em aterros sanitários. Os melhores índices são observados no conjunto dos 15 países (sem considerar os países que aderiram mais recentemente à União Europeia). Na França, por exemplo, 50\% da matéria-prima utilizada na indústria vêm da reciclagem ${ }^{19}$. No Reino Unido, a minimização de resíduos está

\footnotetext{
${ }^{12}$ ABRAMOVAY, Ricardo; SPERANZA, Juliana Simões; PETITGAND, Cécile. Lixo zero: gestão de resíduos sólidos para uma sociedade mais próspera. São Paulo: Planeta Sustentável - Instituto Ethos, 2013. Disponível em: <http://www3.ethos.org.br/cedoc/lixo-zero-gestao-de-residuos-solidos-para-uma-sociedade-mais-prospera/\#.VMf01tJ4qRY>. Acesso em: 12 dez. 2014.

${ }^{13}$ SILVA FILHO, Carlos; SOLER, Fabrício. Gestão de resíduos sólidos: o que diz a Lei. 2. ed. São Paulo: Trevisan Ed., 2013.

${ }^{14}$ MILANEZ, Bruno. Resíduos sólidos e sustentabilidade: princípios, indicadores e instrumentos de ação. 2002. 228f. Dissertação (Mestrado). Centro de Ciências Exatas e de Tecnologia, Universidade de São Carlos, 2002.

${ }^{15}$ ABRAMOVAY, Ricardo; SPERANZA, Juliana Simões; PETITGAND, Cécile. op. cit.

${ }^{16}$ MILANEZ, Bruno. op. cit.

${ }^{17}$ MINISTÉRIO DO MEIO AMBIENTE. Agenda 21. Disponível em: <http://www.mma.gov.br/responsabilidadesocioambiental/agenda-21/agenda-21-global>. Acesso em: 29 jan. 2016.

${ }^{18}$ ABRAMOVAY, Ricardo; SPERANZA, Juliana Simões; PETITGAND, Cécile. op. cit.

${ }^{19}$ Id. Ibid.
} 
no cerne das políticas públicas e, desde o ano 2000, a quantidade de resíduos enviados a aterros caiu $70 \%$ e o índice de reciclagem subiu de $18 \%$ para $44 \%{ }^{20}$.

Estes resultados não são observados nos Estados Unidos, pois a responsabilidade estendida ao produtor foi adotada pelo país apenas em alguns setores, como o de eletroeletrônicos. Por exemplo: apenas 30\% das garrafas PET são reaproveitadas, contra $72 \%$ no Japão ${ }^{21}$.

Como no Brasil a prática da responsabilidade estendida ao produtor é incipiente, os contratos de PPPs devem ser estruturados e articulados com o contexto político e as diretrizes estratégias de governo. É necessário definir de forma clara o escopo contratual e priorizar a eficiência privada, com definição de metas. Especialmente nas concessões de longo prazo, as tecnologias contratadas não devem competir com o mercado de reciclagem, existente ou futuro.

É preciso considerar que, especialmente em mercados de alta rotatividade e inovação tecnológica, devem-se evitar contratos de concessão com prazos muito longos ${ }^{22}$.

Um sistema moderno de gestão de resíduos implica um bom sistema de base de dados, que amplie a responsabilidade e a transparência do governo. Deve-se dar atenção à governança e à sustentabilidade financeira desses serviços, pois a cidade deve cobrir pelo menos os custos de operação no dia a dia; e o uso de tecnologia deve estar conectado com o contexto econômico e social. São diferentes atores que atuam na gestão de resíduos, e o governo deve incentivar tanto o setor empresarial quanto o setor informal ${ }^{23}$.

\section{Método}

A pesquisa realizou estudo de casos em dois editais e minutas de contratos de PPPs, assinados após a publicação da PNRS. Foram consultadas as versões on-line dos editais, disponibilizadas durante a audiência pública e a licitação dos projetos de PPPs ${ }^{24,25}$.

\footnotetext{
${ }^{20}$ GREEN INVESTMENT BANK. The UK residual waste Market. July, 2014. Disponível em: <http://www.greeninvestmentbank.com/media/25376/gib-residual-waste-report-july-2014-final.pdf>. Acesso em: 04 jun. 2015.

${ }^{21}$ ABRAMOVAY, Ricardo; SPERANZA, Juliana Simões; PETITGAND, Cécile. op. cit.

${ }^{22}$ RIBEIRO, Maurício Portugal; PRADO, Lucas Navarro. op. cit.

${ }^{23}$ RODIC, Ljiljana; SCHEINBERG, Anne; WILSON, David. Comparing solid waste management in the world's cities. 5th. World Urban Forum in Rio, 2010. Disponivel em: <http://www.iswa.org/uploads/tx_iswaknowledgebase/Rodic. pdf> Acesso em: 10 jun. 2015.

${ }^{24}$ PREFEITURA MUNICIPAL DE SÃO CARLOS. Edital e Minuta do Contrato Concessão Administrativa dos serviços de limpeza urbana e atividades correlatas. São Carlos, 2008. Disponível em: <http://www.saocarlos. sp.gov.br/images/stories/licitacoes2009/concorrencia_10_09_retificado.pdf>. Acesso em: 10 set. 2013.

${ }^{25}$ PORTAL de Compras MG. Concorrência Pública - 02/2013 - Concessão administrativa dos serviços de transbordo, tratamento e disposição final de resíduos sólidos urbanos da Região Metropolitana de $\mathrm{BH}$ e colar metropolitano - SEDRU. Disponível em:<http://www.compras.mg.gov.br/index.php?option=com_co ntent\&view=article\&id=593:edital-de-ppp-de-residuos-solidos-urbanos-rsu-rmbh\&catid=21\&ltemid=112>. Acesso em: 11 out. 2013.
} 
O objeto de análise foi os indicadores de desempenho utilizados nesses contratos, sob quatro aspectos previstos na PNRS: (a) minimização e não geração de resíduos; (b) mudança na prioridade do tratamento de resíduos; (c) inclusão de catadores de materiais recicláveis; e (d) participação e controle social da população.

Para análise comparativa dos indicadores, foi realizado um mapeamento dos indicadores de limpeza urbana e manejo de resíduos sólidos levantados pelos principais institutos de pesquisas do País, entre eles: $\mathrm{IBGE}^{26}$; Ministério das Cidades - Sistema Nacional de Informações sobre Saneamento (SNIS) 201127; Associação Brasileira de Empresas de Limpeza Pública e Resíduos Especiais (Abrelpe) - Panorama dos Resíduos Sólidos no Brasil 2012 ${ }^{28}$; Instituto de Pesquisas Econômicas Aplicadas (IPEA) - Diagnóstico dos Resíduos Sólidos Urbanos, produzido em 2012 29 ; a pesquisa Coselix, realizada pela Fundação Nacional de Saúde

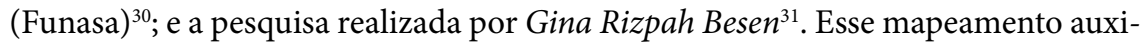
liou na análise dos indicadores de desempenho utilizados nos contratos de PPPs.

A seleção da amostra incluiu dois contratos de PPPs assinados recentemente, após a publicação da PNRS. Foram selecionados os municípios de São Carlos, cujo contrato foi assinado em 2010; e a Região Metropolitana de Belo Horizonte (RMBH) e Colar Metropolitano, cujo contrato foi assinado em 2014.

Em São Carlos, o contrato foi elogiado pelo Tribunal de Contas do Estado (TCE-SP $)^{32}$ por apresentar incentivos financeiros que premiam a concessionária caso haja redução na quantidade de resíduos destinados a aterros. O contrato foi assinado em 23 de agosto de 2010, concomitantemente à publicação da PNRS. Na época, o município

${ }^{26}$ INSTITUTO BRASILEIRO DE GEOGRAFIA E ESTATístICA - IBGE. Pesquisa Nacional de Saneamento Básico 2008. Rio de Janeiro, 2010. Disponível em: <http://www.ibge.gov.br/home/estatistica/populacao/condicaodevida/pnsb2008/defaulttabpdf man_res_sol.shtm>. Acesso em: 11 out. 2013.

${ }^{27}$ BRASIL. MINISTÉRIO DAS CIDADES. Secretaria Nacional de Saneamento Ambiental. Diagnóstico do Manejo de Resíduos Sólidos Urbanos - 2011. Sistema Nacional de Informações sobre Saneamento - SNIS - Resíduos Sólidos -2011. Brasília, 2013. Disponível em: <http://www.snis.gov.br/diagnostico-residuos-solidos>. Acesso em: 07 mar. 2014.

${ }^{28}$ ABRELPE. ASSOCIAÇÃO BRASILEIRA DE EMPRESAS DE LIMPEZA PÚBLICA E RESÍDUOS ESPECIAIS. Panorama de Resíduos Sólidos no Brasil - 2012. ABRELPE. São Paulo, 2012. Disponível em: <http://www. abrelpe.org.br/Panorama/panorama2012.pdf>. Acesso em 17 jan. 2014.

${ }^{29}$ INSTITUTO DE PESQUISA ECONÔMICA APLICADA - IPEA. Diagnóstico dos Resíduos Sólidos Urbanos - Relatório de Pesquisa. Brasília, 2012. Disponível em: <http://www.ipea.gov.br/agencia/images/stories/PDFs/relatoriopesquisa/121009_relatorio_residuos_solidos_urbanos.pdf>. Acesso em 12 mar. 2014.

${ }^{30}$ RIBEIRO, Helena et al. Programas Municipais de coleta seletiva de lixo como fator de sustentabilidade dos sistemas públicos de saneamento ambiental na região metropolitana de São Paulo - Coselix. $4^{\circ}$ Caderno de Pesquisa em Engenharia de Saúde Pública - estudos e pesquisas - FUNASA. Brasília, p. 7-34, 2013. Disponível em: <http://www.funasa.gov.br/site/wp-content/files_mf/iv_caderno_pesquisa_2.pdf>. Acesso em: 20 mar. 2014.

${ }^{31}$ BESEN, Gina Rizpah. Coleta seletiva com inclusão de catadores: construção participativa de indicadores e índices de sustentabilidade. 2011. 274 f. Tese (Doutorado). Faculdade de Saúde Pública, Universidade de São Paulo, São Paulo, 2011.

32 Ver Acórdão TC-006015-026-09 e TC 006103-026-09 - Conselheiro Robson Marinho, Relator. Tribunal Pleno, sessão de 17/06/2009. Disponível em: <http://imprensaoficial.com.br/PortallO/DO/BuscaDO2001Documento_11_4.aspx?link=/2009/legislativo/julho/16/pag_0013_D2C8P60BNKFTNe88LOPBHBLBUOE.pdf\&pagina=13\&data=16/07/2009\&caderno=Legislativo\&paginaordenacao=10013>. 
buscava solução para regularizar a situação do aterro, cuja vida útil estava prevista até dezembro de 2011. O fechamento desse aterro foi acompanhado pela fiscalização da Companhia de Tecnologia de Saneamento Ambiental (Cetesb), através de Termo de Ajustamento de Conduta (TAC). A PPP viabilizou investimentos necessários para a construção do novo aterro, no valor estimado de $\mathrm{R} \$ 18$ milhões - que representava $20 \%$ do total do orçamento da administração direta destinado a investimentos em 2010.

$\mathrm{Na} \mathrm{RMBH}$ e Colar Metropolitano, o contrato agrega 44 municípios conveniados para a gestão regionalizada dos resíduos, visando a ganhos de escala na gestão de resíduos. O convênio foi realizado entre governo do estado e municípios. O contrato de PPP foi assinado em 3 de julho de 2014. O poder concedente é o Governo do Estado de Minas Gerais - através da Secretaria Estadual Extraordinária de Gestão Metropolitana -, e um dos objetivos da PPP é extinguir os lixões da região, adequando a destinação final dos resíduos em aterros sanitários.

Os 44 municípios são divididos em dois lotes, sendo o Lote 1 com 26 municípios e o Lote 2 com 18 municípios. Os municípios de Belo Horizonte, Sabará, Brumadinho e Itabirito não aderiram, pois já desenvolvem programas específicos na gestão de resíduos urbanos ${ }^{33}$.

\section{Resultados e discussão}

A análise dos editais revelou que o objeto principal contratado não inclui diretrizes para minimização de resíduos em aterros e mudança na ordem de tratamento de resíduos, como definido na PNRS. O objeto principal está vinculado ao antigo paradigma de coleta e transporte de resíduos e operação de aterros sanitários, com captação de gases para geração de energia, em projetos de Mecanismos de Desenvolvimento Limpo (MDL).

A principal diretriz nos contratos analisados é contratar infraestrutura e operação de aterros sanitários para adequar a destinação final dos resíduos, com fechamento dos lixões ainda existentes.

Para a minimização de resíduos, os contratos possuem mecanismos de incentivo financeiro à redução de resíduos em aterros, no entanto não há metas contratuais fixas.

Um importante instrumento desses contratos são as receitas acessórias obtidas pela concessionária, que são oriundas: da captação de gás nos aterros com geração de energia; do recebimento de resíduos de outros municípios; e do

\footnotetext{
${ }^{33}$ GOVERNO DO ESTADO DE MINAS GERAIS. Secretaria Extraordinária de Gestão Metropolitana. Plano Metropolitano de Resíduos Sólidos: Região Metropolitana de Belo Horizonte e Colar Metropolitano. Belo Horizonte-MG, 2013. Disponível em: <http://www.metropolitana.mg.gov.br/system/attachments/148/ original/2013_02_06_PLANO-METROPOLITANO-RES\%C3\%8DDUOS-S\%C3\%93LIDOS_v20. pdf?1366985211>. Acesso em: 29 jan. 2016.
} 
tratamento alternativo de resíduos. No contrato de PPP da Região Metropolitana de Belo Horizonte e Colar Metropolitano, os estudos preliminares indicaram que essas receitas acessórias podem atingir $50 \%$ da remuneração da concessionária, sendo um importante elemento de flexibilidade e ajuste contratual ao longo da concessão.

A seguir apresentamos os principais pontos de discussão.

\section{Objeto do contrato e forma de pagamento}

No município de São Carlos, o objeto principal inclui: coleta e transporte dos resíduos sólidos domiciliares e dos resíduos dos serviços de saúde; construção e operação de aterros sanitários, com captação de gás para geração de energia. A captação do biogás é obrigatória no aterro novo, e opcional no aterro antigo.

O contrato não inclui os serviços indivisíveis de limpeza urbana, e o prazo de vigência é de 20 anos, renováveis por mais dez anos. Para remuneração da concessionária, estudos de referência para o projeto de PPP definiram um valor médio de R $\$ 797$ mil para a contraprestação fixa mensal, e a base de cálculo foi estipulada com base no índice de coleta do ano de 2008 - em média, 4.418,59 toneladas/mês, resultando em um valor de $\mathrm{R} \$ 180 /$ tonelada. O valor total do contrato é de R\$ 179 milhões (valores de abril de 2008), somando-se todas as contraprestações mensais.

A remuneração é composta pelo pagamento dos serviços de coleta, transporte e disposição final de resíduos em aterros, deduzidos os valores das receitas acessórias recebidas pela Sociedade de Propósito Específico (SPE) e acrescida a premiação referente aos indicadores de desempenho (cláusula 17.01 do edital).

$\mathrm{Na}$ RMBH e Colar Metropolitano, o objeto principal inclui serviços de transbordo, tratamento e disposição final de resíduos sólidos urbanos, em todos os municípios convenentes. O objeto da PPP não inclui a coleta convencional e a coleta seletiva, que continuam sob responsabilidade das prefeituras municipais (anexo II - minuta do contrato, cláusula $5^{\mathrm{a}}$, item 5.1). A concessionária é obrigada a implantar as estações de transbordo situadas em um raio máximo de 12 $\mathrm{km}$ dos centros dos municípios. O prazo contratual é de 30 anos, prorrogáveis por mais cinco anos.

O valor total do contrato estimado para o Lote 1 é de $\mathrm{R} \$ 1.199 .510 .756,63$ (um bilhão, cento e noventa e nove milhões, quinhentos e dez mil, setecentos e cinquenta e seis reais e sessenta e três centavos) e para o Lote 2, de R $\$ 1.243 .199 .228,59$ (um bilhão, duzentos e quarenta e três milhões, cento e noventa e nove mil, duzentos e vinte e oito reais e cinquenta e nove centavos) - cláusula $5^{a}$ do edital, resultando em um valor por tonelada de destinação de resíduos (VPTD) teto de $\mathrm{R} \$ 79,18$ (setenta e 
nove reais e dezoito centavos) no Lote 1 e de $\mathrm{R} \$ 72,18$ (setenta e dois reais e dezoito centavos) no Lote 2 , cláusula 16.5 do edital ${ }^{34}$.

O pagamento da concessionária será feito pelo governo do estado, por quantidade (tonelada) de resíduos sólidos urbanos efetivamente destinados às estações de transbordo (edital, anexo V, item 1.3). O convênio de cooperação entre governo do estado e municípios define que os municípios farão o pagamento no valor de $\mathrm{R} \$$ 18 por tonelada efetivamente entregue às estações de transbordo. O restante é pago com verbas do governo do estado e representa em torno de $75 \%$ do valor total da contraprestação. O pagamento será mensal e sofrerá impacto dos indicadores, que poderão acrescentar ao valor da contraprestação mensal até $40 \%$, segundo desempenho da concessionária.

Além disso, há previsão de receitas acessórias, que serão compartilhadas na proporção de $30 \%$ para o Estado (rebatidas no valor da contraprestação) e $70 \%$ para o parceiro privado (cláusula 22.1 da minuta do contrato). As receitas acessórias preveem a comercialização de energia, tanto no tratamento térmico de resíduos, quanto pelo aproveitamento de gás metano de aterros. Nos estudos desenvolvidos, as receitas acessórias podem representar 50\% do montante de contraprestação previsto no contrato. Caso o montante das receitas acessórias ultrapasse 30\% das receitas totais da SPE por dois anos consecutivos, há previsão de reequilíbrio do contrato a favor do poder concedente (anexo III, cláusula 3.2).

\section{Minimização de resíduos e metas contratuais}

Nos contratos analisados, não há metas fixas para minimização de resíduos ou para formas alternativas de tratamento de resíduos como reciclagem, compostagem, entre outras. O mecanismo utilizado são instrumentos de incentivo financeiro, que podem ser utilizados a critério do plano de negócios da concessionária. Com isso, prioriza-se o uso de instrumentos econômicos em detrimento dos instrumentos de comando e controle ${ }^{35}$.

No município de São Carlos, a concessionária é responsável pela coleta convencional e seletiva de resíduos, no entanto o contrato de PPP não define metas para universalização da coleta seletiva, por exemplo.

O mecanismo financeiro consiste em um acréscimo na receita (acessória) da concessionária proporcional à redução na quantidade per capita de resíduos (autóctones) dispostos em aterro (anexo I, Termo de Referência, cláusula 2.11.1.1).

${ }^{34} \mathrm{~A}$ empresa vencedora ofereceu o valor por tonelada de $\mathrm{R} \$ 79,13$ para o Lote 1 e $\mathrm{R} \$ 72,13$ para o Lote 2 . PORTAL de Compras MG. Concorrência Pública - 02/2013 - Concessão administrativa dos serviços de transbordo, tratamento e disposição final de resíduos sólidos urbanos da Região Metropolitana de $\mathrm{BH}$ e colar metropolitano - SEDRU, cit.

${ }^{35}$ MILANEZ, Bruno. op. cit. 
Assim, uma redução de 5\% na disposição per capita de resíduos em aterros gera um aumento de $5 \%$ sobre a receita complementar obtida pela concessionária.

Existem algumas obrigações contratuais para minimização dos resíduos, como exemplo: a concessionária é obrigada a implantar uma central de triagem (anexo I, item 9), cujo valor foi estimado em R\$ 1,2 milhão (anexo XIX do edital). A concessionária poderá implantar outras centrais de triagem a suas expensas. $\mathrm{O}$ contrato também prevê atividades de educação ambiental e campanhas educativas realizadas pela concessionária, porém não há metas específicas para essas atividades.

No contrato da RMBH e Colar Metropolitano, o incentivo financeiro consiste no quadro de indicadores de desempenho, que pode aumentar em $40 \%$ o valor da contraprestação mensal da concessionária.

Além desse incentivo financeiro, a concessionária deve implantar centrais para tratamento de resíduos e tratar parte dos resíduos destinados às estações de transbordo. Na elaboração dos estudos, houve grande polêmica sobre o uso de incineração (tratamento térmico) como forma de tratamento e desvio de resíduos de aterros. Esse tema não está pacificado no país. A solução adotada não proibiu a incineração dos resíduos (visto que a proibição é ilegal do ponto de vista concorrencial), mas, a incineração não foi incluída nos critérios utilizados pelo Quadro de Indicadores (QID), não sendo computada no cálculo da premiação.

Para a minimização dos resíduos, a concessionária também é obrigada a apresentar Programa de Educação Ambiental Participativo, que será executado junto à prefeitura local, concomitantemente à operação da Central de Tratamento de Resíduos (anexo VI, item 3.6.1.5).

\section{Indicadores de desempenho}

Os indicadores utilizados para medir o desempenho das concessionárias estão relacionados principalmente ao objeto contratado e à quantidade de resíduos coletados e aterrados. Por meio desses indicadores, pode-se medir também o desvio de resíduos de aterros.

No contrato de São Carlos, os indicadores de desempenho monitoram a operação do serviço contratado (escopo principal do contrato). A concessionária deve apresentar mensalmente a quilometragem percorrida pelo setor de coleta, bem como os demais indicadores operacionais para fins de controle estatístico (anexo I, itens 2.1.13, 2.1.14 e 2.11, metas do contrato). Dessa forma, a premiação pelo desvio de resíduos em aterros ocorre pelo controle da quantidade de resíduos disposta em aterros na operação da concessionária.

$\mathrm{Na} \mathrm{RMBH}$ e Colar Metropolitano, os indicadores de desempenho avaliam quatro aspectos principais, sendo que um deles avalia o desvio de resíduos em 
aterros. Em síntese, os quatro indicadores avaliam: (a) a operação das estações de transbordo (IPET); (b) a operação do aterro sanitário (IDDF); (c) o desvio de resíduos em aterros (IRRA); e (d) o coeficiente ambiental (CA) que mede a disposição da concessionária de desviar os resíduos dos aterros (foi utilizado também como critério de julgamento na licitação - menor preço e maior índice de desvio de aterro). O coeficiente varia de 0,2 a 1 e, quanto mais próximo do 1, maior a disposição de evitar a disposição de resíduos em aterros. Esse coeficiente funciona como um multiplicador e amplia o impacto do indicador de desvio de resíduos dispostos em aterros. Quanto maior o CA, maior a disposição de reduzir o uso de aterros. Segue a fórmula para o cálculo do QID (anexo 1, item 2.1.3.1):

$$
\mathrm{QID}_{\text {LoteJ }}=\left\{\frac{\mathrm{IPET}_{\text {LoteJ }}+\left[\left(1-\mathrm{CA}_{\text {LoteJ }}\right)+\left(2-\mathrm{CA}_{\text {otej }} \times \mathrm{IRRA}_{\text {LOteJ }}\right)\right]}{2}\right\} \times \operatorname{IDDF}_{\text {LOteJ }}
$$

Também não há metas específicas para formas alternativas de tratamento de resíduos, havendo apenas o mecanismo de incentivo financeiro do QID.

A contraprestação é paga em duas parcelas. A primeira parcela é mensal, dada pela quantidade total de resíduos destinados às estações de transbordo, multiplicada pelo valor licitado ( $\mathrm{R}$ /tonelada). Sobre essa parcela incide o QID, que pode acrescer em até $40 \%$ o valor das receitas obtidas pela concessionária. A segunda parcela é uma contraprestação complementar, paga anualmente, para compartilhar os riscos decorrentes de uma redução na quantidade de resíduos destinados às estações de transbordo pelas prefeituras. Essa contraprestação complementar só é paga caso o montante de resíduos destinados às estações de transbordo seja inferior a $70 \%$ da quantidade/ano estimada pelo contrato. Dessa forma, há um compartilhamento de riscos entre Estado e concessionária em relação à demanda (quantidade de resíduos efetivamente destinados pelas prefeituras). A concessionária assume o risco até a banda de $30 \%$ de variação. Acima disso, o risco é assumido pelo Governo do Estado, através da contraprestação complementar.

\section{Projeção inicial na geração de resíduos e revisões contratuais}

Os estudos que embasaram a elaboração do edital e do contrato, nos dois casos analisados, apresentaram estimativas conservadoras para a quantidade gerada e/ou coletada de resíduos sólidos urbanos ao longo da concessão. Com base nessas projeções, foi calculada a receita total dos contratos que embasa as revisões contratuais.

O contrato do São Carlos utilizou a quantidade mensal coletada no ano-base de 2008. Na RMBH e Colar Metropolitano, o estudo apresentou uma estimativa de geração de resíduos que considera um crescimento médio de $30 \%$ na geração de resíduos, com base no crescimento populacional e no crescimento do Produto Interno Bruto (PIB). 
Sobre essas projeções, os contratos possuem revisões periódicas que permitem ajustes graduais e progressivos, respeitando o equilíbrio econômico-financeiro do contrato.

No contrato de São Carlos, há cláusulas para revisões ordinárias, realizadas a cada cinco anos, para revisão da contraprestação e para recomposição das condições iniciais do contrato, preservando o reequilíbrio econômico-financeiro (anexo XI, minuta do contrato, cláusula 17.07).

No contrato da RMBH e Colar Metropolitano, a projeção inicial de resíduos será revisada a cada quatro anos, permitindo ajustes na projeção anual de resíduos sólidos urbanos (RSU) para o quadriênio seguinte. Esse ajuste é limitado a uma variação de até $10 \%$ (para cima ou para baixo) da projeção anterior. Ao longo da concessão, serão realizadas sete revisões quadrienais, possibilitando a flexibilização do contrato a políticas de minimização de resíduos, realizadas pelo poder público e pelas prefeituras.

Assim, as políticas de minimização de resíduos e de coleta de resíduos permanece a cargo do poder público, e o contrato de PPP apresenta mecanismos de flexibilização caso as ações do poder público para minimização na disposição final de resíduos surtam efeito. No entanto, visando garantir o equilíbrio econômico-financeiro, a variação é gradual, ficando aquém das diretrizes definidas pela PNRS para a alteração na prioridade do tratamento de resíduos e minimização de resíduos em aterros.

Não há metas fixas para minimização de resíduos e para valorização dos materiais com formas alternativas de tratamento. Essas metas estão previstas nos respectivos Planos de Gestão Integrada de Resíduos Sólidos Urbanos, como veremos a seguir.

\section{Valorização dos materiais e formas alternativas de tratamento de resíduos}

As metas da gestão para valorização dos materiais e tratamento alternativo dos resíduos estão explicitadas nos respectivos Planos de Gestão Integrada de Resíduos Sólidos, ou no Plano Municipal de Saneamento, como define a PNRS.

O Plano Municipal de Saneamento de São Carlos foi publicado em março de 2012, dois anos após a assinatura do contrato de PPP. O plano prevê as seguintes metas para reciclagem: $4 \%$ em 2015; $8 \%$ em 2020; e 14\% em 2030. As metas para compostagem de resíduos orgânicos são: 14\% em 2015; 24\% em 2020; e 44\% em 2030; além de prever ações nas diferentes áreas da gestão de resíduos ${ }^{36}$.

\footnotetext{
${ }^{36}$ PREFEITURA MUNICIPAL DE SÃO CARLOS. Plano Municipal de Saneamento do Município de São Carlos (PMSSanCa). Disponível em: <http://www.saocarlos.sp.gov.br/index.php/meio-ambiente/159636-planomunicipal-de-saneamento.html>. Acesso em: 29 jan. 2016.
} 
O contrato de PPP não inclui essas metas, pois a publicação do Plano de Saneamento foi posterior à assinatura da PPP. No entanto, essas metas poderão ser incorporadas, ao longo da concessão, visto que o contrato possui mecanismos de ajuste de metas (anexo I, termo de referência, cláusula 2.11.2.4), com revisões periódicas a cada cinco anos.

$\mathrm{Na}$ RMBH e Colar Metropolitano, o Plano Metropolitano de Resíduos Sólidos (página 162) prevê metas de universalização da coleta seletiva até o ano de 2016, incluindo metas para os índices de comercialização de materiais para reciclagem. No ano de 2016, os índices de comercialização de recicláveis deverão ser de no mínimo 0,5\% nos municípios que ainda não possuem organização de catadores; $2 \%$ nos municípios com até 50 mil habitantes; e 1\% nos municípios com mais de 50 mil habitantes. Essas metas também estão presentes no convênio realizado entre governo do estado e municípios.

Além disso, o plano prevê metas para diagnosticar os catadores da região, criar organizações e cadastrá-las no Programa Bolsa Reciclagem. Para disposição final dos resíduos, o plano define que, até 2014, 100\% dos resíduos teriam destinação adequada, conforme preconizado pela PNRS.

As metas definidas para a RMBH e Colar Metropolitano também não foram incorporadas ao contrato de PPP. Muitas dessas metas dependem da esfera governamental - estado ou prefeituras -, mas cabe averiguar se os mecanismos de incentivo financeiro serão suficientes para adequar o contrato de PPP às metas definidas pela própria gestão.

\section{Inclusão de catadores e participação da sociedade civil}

A relação com os catadores de materiais recicláveis permanece com a prefeitura e não foi incluída nos contratos de PPP analisados.

É interessante manter a relação direta entre catadores e prefeitura, garantindo o interesse público na inclusão social e emancipação econômica, como preconizado pela PNRS. Nesse sentido, os contratos de PPPs preveem a realização de parcerias entre Prefeitura e catadores, preservando o espaço de atuação dos catadores na coleta, triagem e comercialização dos materiais, em paralelo ao contrato de concessão.

Para garantir o controle social e a participação da sociedade civil, a PNRS prevê mecanismos para ampliar a participação social na gestão de resíduos. O principal mecanismo é a revisão do Plano Municipal de Gestão Integrada de Resíduos (PGRIS), sob responsabilidade das esferas de governo, que deve ser feita a cada quatro anos e validada em audiências públicas.

O contrato de PPP de São Carlos não apresenta nenhum mecanismo específico para ampliar a participação social no controle da PPP. No contrato da RMBH, o anexo VII descreve o modelo de governança, que prevê um Comitê com oito membros, cuja composição é: seis membros do poder público, um da concessionária e um da sociedade civil - sendo este representado por um catador indicado pelo 
Movimento Nacional de Catadores de Materiais Recicláveis (MNCR). Nesse aspecto, o contrato de PPP da RMBH e Colar Metropolitano inova e avança na discussão sobre a participação de conselhos de usuários em contratos de concessão, conforme previsto no artigo 30 da Lei de Concessões. O modelo de governança prevê também relatórios de prestação de contas e um site para divulgação de informações.

\section{Considerações finais}

A pesquisa revelou que o objeto principal dos contratos analisados está atrelado ao antigo paradigma da gestão de resíduos - coleta e transporte de resíduos e operação de aterros sanitários, com captação de energia em aterros - e não inclui, no escopo principal, diretrizes para minimização de resíduos em aterros. Os contratos possuem apenas mecanismos de incentivo financeiro para o desvio de resíduos em aterros, com cláusulas para ajustes periódicos e graduais.

Um elemento importante para a flexibilidade nos contratos analisados são as receitas acessórias, oriundas de diversas fontes: da comercialização de energia captada dos aterros sanitários; de formas alternativas de tratamento de resíduos; e do recebimento de resíduos de outros municípios. Os ganhos da concessionária com as receitas acessórias serão compartilhados com o poder público e constituem um elemento importante de flexibilidade contratual, para ajustes de longo prazo.

No entanto, os contratos não definem metas fixas para mudança na prioridade do tratamento dos resíduos e para minimização de resíduos em aterros.

Como discutido, os melhores resultados no benchmarking internacional resultam do uso misto de instrumentos de comando e controle, instrumentos econômicos e instrumentos voluntários, e o poder público tem um papel central na articulação desses instrumentos e na definição das diretrizes estratégicas.

Neste cenário, os contratos de PPPs devem ser estruturados e articulados com as diretrizes de governo e prever metas fixas de desempenho que estimulem a eficiência da iniciativa privada para implementação das políticas públicas de minimização de resíduos em aterros. Além disso, as metas contratuais devem ampliar o diálogo com as metas definidas pela gestão nos respectivos Planos de Gestão Integrada de Resíduos Sólidos.

A gestão de resíduos deve desprivilegiar o uso de aterros e incentivar formas alternativas de tratamentos de resíduos, considerando também a possibilidade de uma gestão descentralizada dos resíduos sólidos urbanos, criando nichos de atuação para diferentes empreendimentos, incentivando o setor empresarial e o setor informal e fortalecendo o conceito de resíduo como um bem ambiental, econômico e social, gerador de trabalho e renda e promotor da cidadania, como previsto no artigo $6^{\circ}$, inciso VIII, da Lei n. 12.305/2010. 


\section{Referências}

ABRAMOVAY, Ricardo; SPERANZA, Juliana Simões; PETITGAND, Cécile. Lixo zero: gestão de resíduos sólidos para uma sociedade mais próspera. São Paulo: Planeta Sustentável - Instituto Ethos, 2013. Disponível em: <http://www3.ethos.org.br/cedoc/lixozero-gestao-de-residuos-solidos-para-uma-sociedade-mais-prospera/\#.VMf01tJ4qRY >. Acesso em: 12 dez. 2014.

ABRELPE. ASSOCIAÇÃO BRASILEIRA DE EMPRESAS DE LIMPEZA PÚBLICA E RESÍDUOS ESPECIAIS. Panorama de Resíduos Sólidos no Brasil - 2012. ABRELPE. São Paulo, 2012. Disponível em: <http://www.abrelpe.org.br/Panorama/panorama2012.pdf>. Acesso em 17 jan. 2014.

BESEN, Gina Rizpah. Coleta seletiva com inclusão de catadores: construção participativa de indicadores e índices de sustentabilidade. 2011.274 f. Tese (Doutorado). Faculdade de Saúde Pública, Universidade de São Paulo, São Paulo, 2011.

BRASIL. MINISTÉRIO DAS CIDADES. Secretaria Nacional de Saneamento Ambiental. Diagnóstico do Manejo de Resíduos Sólidos Urbanos - 2011. Sistema Nacional de Informações sobre Saneamento - SNIS - Resíduos Sólidos -2011. Brasília, 2013. Disponível em: <http://www.snis.gov.br/diagnostico-residuos-solidos>. Acesso em: 07 mar. 2014.

BRITO, Barbara Moreira Barbosa; SILVEIRA, Antônio Henrique Pinheiro. Parceria público-privada: compreendendo o modelo brasileiro. Revista do Serviço Público, Brasília v. 56, n. 1, p. 7-21, jan./mar. 2005. Disponível em: <seer.enap.gov.br/index.php/RSP/issue/ download/38/49>. Acesso em: 11 mar. 2014.

DI PIETRO, Maria Sylvia Zanella. Parcerias na administração pública: concessão, permissão, franquia, terceirização, parceria público-privada e outras formas. 7. ed. São Paulo: Atlas, 2009.

GOVERNO DO ESTADO DE MINAS GERAIS. Secretaria Extraordinária de Gestão Metropolitana. Plano Metropolitano de Resíduos Sólidos: Região Metropolitana de Belo Horizonte e Colar Metropolitano. Belo Horizonte-MG, 2013. Disponível em: <http:// www.metropolitana.mg.gov.br/system/attachments/148/original/2013_02_06_PLANOMETROPOLITANO-RES\%C3\%8DDUOS-S\%C3\%93LIDOS_v20.pdf?1366985211>. Acesso em: 29 jan. 2016.

PORTAL de Compras MG. Concorrência Pública - 02/2013 - Concessão administrativa dos serviços de transbordo, tratamento e disposição final de resíduos sólidos urbanos da Região Metropolitana de BH e colar metropolitano - SEDRU. Disponível em: $<$ http://www. compras.mg.gov.br/index.php?option=com_content\&view=article\&id=593:edital-de-pppde-residuos-solidos-urbanos-rsu-rmbh\&catid=21\&Itemid=112>. Acesso em: 11 out. 2013.

GREEN INVESTMENT BANK. The UK residual waste Market. July, 2014. Disponível em: $<$ http://www.greeninvestmentbank.com/media/25376/gib-residual-waste-report-july-2014final.pdf>. Acesso em: 04 jun. 2015. 
INSTITUTO BRASILEIRO DE GEOGRAFIA E ESTATÍSTICA - IBGE. Pesquisa Nacional de Saneamento Básico 2008. Rio de Janeiro, 2010. Disponível em: <http://www.ibge.gov.br/ home/estatistica/populacao/condicaodevida/pnsb2008/defaulttabpdf_man_res_sol.shtm>. Acesso em: 11 out. 2013.

INSTITUTO DE PESQUISA ECONÔMICA APLICADA - IPEA. Diagnóstico dos Resíduos Sólidos Urbanos - Relatório de Pesquisa. Brasília, 2012. Disponível em: <http://www.ipea. gov.br/agencia/images/stories/PDFs/relatoriopesquisa/121009_relatorio_residuos_solidos_ urbanos.pdf $>$. Acesso em 12 mar. 2014.

MELLO, Celso Antônio Bandeira de. Curso de direito administrativo. 27. ed. rev. atual. até a Emenda Constitucional 64, de 4.2.2010. São Paulo: Malheiros Ed., 2010.

MILANEZ, Bruno. Resíduos sólidos e sustentabilidade: princípios, indicadores e instrumentos de ação. 2002. 228f. Dissertação (Mestrado). Centro de Ciências Exatas e de Tecnologia, Universidade de São Carlos, 2002.

PREFEITURA MUNICIPAL DE SÃO CARLOS. Edital e Minuta do Contrato Concessão Administrativa dos serviços de limpeza urbana e atividades correlatas. São Carlos, 2008. Disponível em: <http://www.saocarlos.sp.gov.br/images/stories/licitacoes2009/ concorrencia_10_09_retificado.pdf>. Acesso em: 10 set. 2013.

. Plano Municipal de Saneamento do Município de São Carlos (PMSSanCa). Disponível em: <http://www.saocarlos.sp.gov.br/index.php/meio-ambiente/159636-plano-municipal-desaneamento.html>. Acesso em: 29 jan. 2016.

RIBEIRO, Helena et al. Programas Municipais de coleta seletiva de lixo como fator de sustentabilidade dos sistemas públicos de saneamento ambiental na região metropolitana de São Paulo - Coselix. $4^{\circ}$ Caderno de Pesquisa em Engenharia de Saúde Pública - estudos e pesquisas - FUNASA. Brasília, p. 7-34, 2013. Disponível em: <http://www.funasa.gov.br/site/ wp-content/files_mf/iv_caderno_pesquisa_2.pdf $>$. Acesso em: 20 mar. 2014.

RIBEIRO, Maurício Portugal; PRADO, Lucas Navarro. Comentários à Lei de PPP - Parceria Público-Privada: fundamentos econômico-jurídicos. São Paulo: Malheiros Ed., 2007.

RODIC, Ljiljana; SCHEINBERG, Anne; WILSON, David. Comparing solid waste management in the world's cities. 5th. World Urban Forum in Rio, 2010. Disponível em: <http://www.iswa. org/uploads/tx_iswaknowledgebase/Rodic.pdf> Acesso em: 10 jun. 2015.

SILVA FILHO, Carlos; SOLER, Fabrício. Gestão de resíduos sólidos: o que diz a Lei. 2. ed. São Paulo: Trevisan Ed., 2013.

\section{Agradecimentos}

Em especial às professoras que contribuíram para esta pesquisa, durante a conclusão da especialização lato sensu em Gestão Pública, na Escola de Contas do Tribunal de Contas do Município de São Paulo (TCM-SP): Profa. Izabel Camargo 
Lopes Monteiro, Profa. Wanda Maria Risso Günther e Profa. Karina Houat Harb, e aos colegas que contribuíram com a leitura, em especial Gina Rizpah Besen e Dan Moche Schneider.

Christine Parmezani Munhoz - Especialização Lato Sensu em Administração Pública, Escola de Contas do Tribunal de Contas do Município de São Paulo. São Paulo/SP, Brasil. E-mail: chrismunhoz@yahoo.com.br. 